\title{
Factors of Post-operative wound infection in abdominal surgeries of Obstetrics and Gynaecology department
}

\author{
Jahanara Rahman ${ }^{1}$, Nasreen Sultana ${ }^{2}$, Munir Hasan ${ }^{3}$, Hosne Ara Begum ${ }^{4}$ \\ ${ }^{1}$ Associate Professor,Department of Obstetrics and Gynaecology, Dhaka National Medical College, ${ }^{2}$ Assistant Professor, Department of \\ Obstetrics and Gynaecology,Dhaka National Medical College, ${ }^{3}$ Head of the department of Microbiology, Dhaka National Medical \\ College, ${ }^{4}$ Head of the department of Obstetrics and Gynaecology, Dhaka National Medical College.
}

\begin{abstract}
A cross-sectional descriptive study was carried out in Obstetrics and Gynecology department, unit I of Dhaka National Medical College Hospital between June 2010 and May 2011. The objectives of the study were to find out the predisposing factors and to identify the organism causing post-operative wound infection. Out of 530 patients who underwent major abdominal surgery, 40 developed wound infection and were included in this study. Mean age of the population was $29.73 \mathrm{SD} \pm 94$, ranges 18 to 60 years, all were female, $75 \%$ of them were literate and $55 \%$ respondents came from middle class and affluent society. Sixty percent population was multiparous. Anaemia and raised blood sugar was found in $70 \%$ and $27 \%$ of the population respectively. The respondents under went caesarean section $(\mathbf{7 1 \%})$, total abdominal hysterectomy (27\%) and laparotomy $(2 \%)$. Wound infection appeared within 5 th day, $6^{\text {th }}$ to 10 th day and beyond $10^{\text {th }}$ day of operation in $22.5 \%$, $52.5 \%$ and $25 \%$ cases respectively. Wound discharge was serosanguinous in $50 \%$ cases. Bloody, purulent and no discharge was found in $10 \%, 30 \%$ and $10 \%$ wound respectively. Growth of Staphylococcus was noticed in 30\% culture wound swab. Besides this, E coli, Pseudomonas, Klebsiella, Mycobacterium tuberculosis and other Coliform bacilli was found in $20 \%, 5 \%, 5 \%, 2.5 \%$ and $2.5 \%$ of growth. In $35 \%$ cases no growth of organism took place.
\end{abstract}

Key words: Wound infection, factors, abdominal surgery

\section{Introduction:}

Post-operative wound infection is a major complication of surgery. The manifestation of postoperative wound infection has a tri-factorial basis: the overall systemic trauma, local host damage, and bacterial contamination of the wound. Every wound is able to tolerate some local host damage and some bacterial inoculums without manifestation of infection. But when local host damage and bacterial inoculums exceed the tolerable threshold, infection will become manifest. The level of this breaking point may depend on certain systemic host factors such as age, diabetes, anaemia, malnutrition and immunodeficiency 1 . On the other hand post-operative wound infection following caesarean section is related with some other factors like, prolonged rupture of membrane, prolonged labour, emergency rather than elective caesarean section ${ }^{2}$.In any surgical wound presence of foreign bodies, trauma, haematoma etc enhance the effect of bacterial inoculum ${ }^{3}$. Bacteria can infect through two major sources, endogenous and exogenous. E coli, Pseudomonas, Staphylococcus aureas, Streptococcus pyogenes, Klebsiella are common organism infect a surgical wound. Of them Staphylococcus aureus and Streptococcus pyogenes have a greater propensity to cause post-operative wound infection ${ }^{4,5}$.

Materials and methods:

A cross-sectional descriptive study was carried out in inpatient Obstetrics and Gynaecology department, unit I of Dhaka National Medical College Hospital between June 2010 and May 2011.The objectives of the study was to find out the predisposing factors responsible for wound infection and to identify the organism causing wound infection. The patients developed wound infection following major abdominal surgery in the department of Gynecology and Obstetrics, unit -I were included in this study. A pre-tested structured questionnaire containing the related variables was used for collecting data by face to face interview. The wound was checked on $5^{\text {th }}$ post-operative day routinely and earlier and later according to the complaint of the respondents. Wound swabs were sent for culture and sensitivity where discharge from the wound was present. An experienced laboratory technician of the department of pathology of DNMCH collected blood samples for assessing haemoglobin and blood sugar estimation. The 
J. Dhaka National Med. Coll. Hos. 2011; 18 (01): 39-42 collected data was checked, edited and coded and was analysed using EPI-Info and SPSS programmers. The test of significance was done at $95 \%$ confidence interval.

\section{Results:}

During the study period, 530 patients underwent major abdominal surgery in Obstetrics and Gynecology department, unit-I of Dhaka National Medical College Hospital. Of them forty patients developed postoperative wound infection. Mean age of the population was $29.73 \mathrm{SD} \pm 94$, ranges 18 to 60 years, being the patients of Obstetrics and Gynaecology all were female. Majority $(87.5 \%)$ of the population was housewives. Regarding the educational status one quarter of the patients was illiterate. Others were educated upto class V, class VIII, SSC, HSC and above 17.5\%, 15\%, 17.5\% and $25 \%$ respectively. More than half of the population (55\%) was from middle class and affluent society. Rest $(45 \%)$ was from low socio-economic status. Sixty percent $(n=24)$ respondents were multiparous. Types of surgery done among the wound infected population were caesarean section $(\mathrm{n}=29)$, total abdominal hysterectomy $(n=10)$ and laparotomy due to ruptured ectopic pregnancy $(n=1)$. Of the caesarean sections 23 cases were performed due to emergency indication and 17 cases were performed electively. Anaemia and raised blood sugar was found in $70 \%$ and $27 \%$ of the respondents respectively. Very negligible number of respondents $(\mathrm{n}=2)$ had respiratory tract infection and others had no infection in any other part of the body. One third of the respondents had raised body temperature. In $52.5 \%$ of the population infection appeared within 6 to10 day of operation. Infection appeared within 5th day and beyond 10th day of surgery in $22.5 \%$ and $25 \%$ respondents respectively. The wound was presented with serosanguinous discharge in 50\% cases. Bloody, purulent and no discharge was found in $10 \%, 30 \%$ and $10 \%$ cases respectively. Growth of Staphylococcus was found predominantly $(30 \%)$ in the culture of the wound swab. E.coli and Pseudomonas was found in 20\% and 5\% cases. Growth of Klebsiella, M. tuberculosis and other Coliform bacilli was found in 5\%, $2.5 \%$ and $2.5 \%$ cases also. In $35 \%$ cases no growth of bacteria was found. Wounds were healed by secondary suture (52\%), dressing and antibiotic (40\%), only antibiotic $(5 \%)$ and tertiary suture $(3 \%)$.

\section{Figures and tables}

Fig 1-

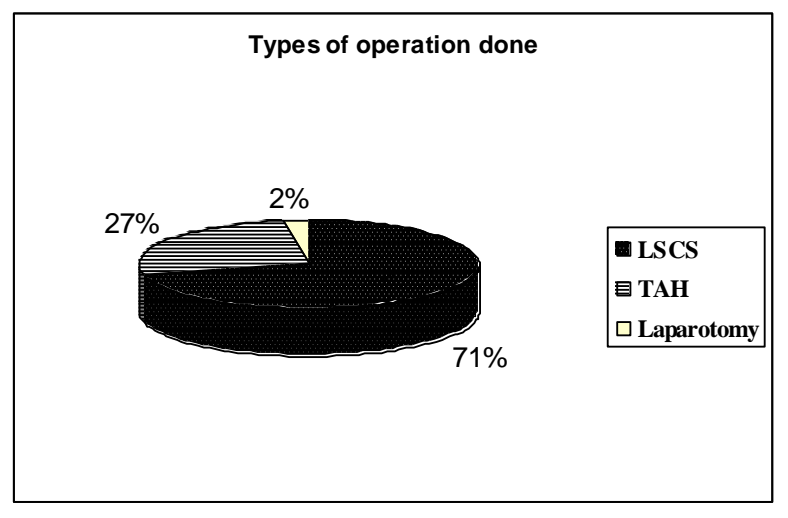

Fig 2-

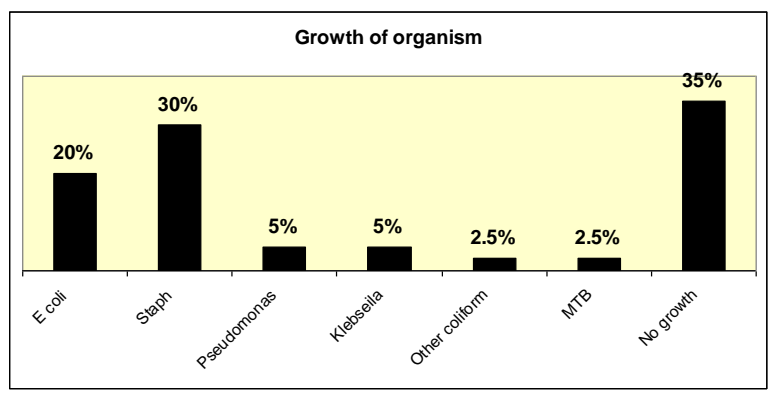

Fig 3-

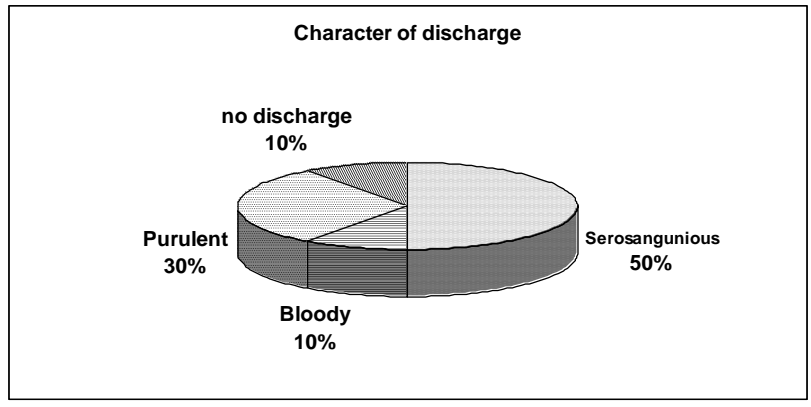


J. Dhaka National Med. Coll. Hos. 2011; 18 (01): 39-42

Fig 4-

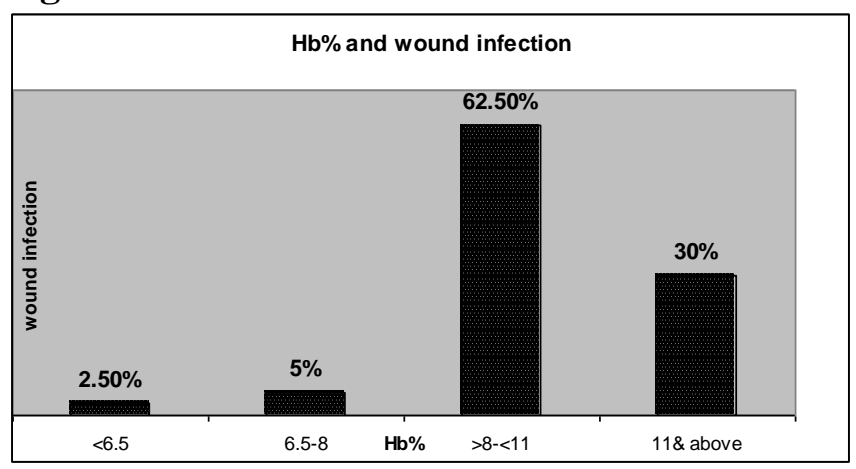

Fig 5-

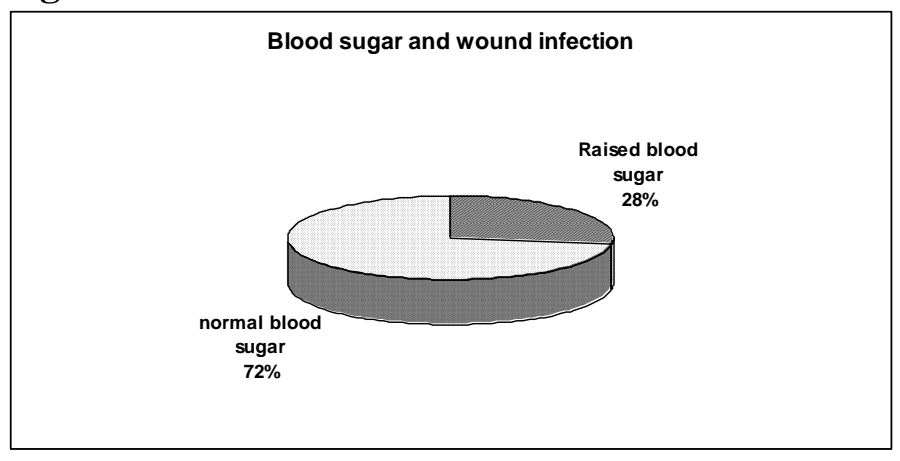

Table-I

\begin{tabular}{|l|l|l|l|}
\hline \multicolumn{4}{|l|}{ Signs other than wound discharge } \\
\hline $\begin{array}{l}\text { Only } \\
\text { induration }\end{array}$ & $\begin{array}{l}\text { Wound } \\
\text { gap }\end{array}$ & $\begin{array}{l}\text { Raised local } \\
\text { temperature }\end{array}$ & $\begin{array}{l}\text { No } \\
\text { other } \\
\text { sign }\end{array}$ \\
\hline 8 & 25 & 1 & 6 \\
\hline
\end{tabular}

Table- II

\begin{tabular}{|l|l|l|}
\hline $\begin{array}{l}\text { Post-operative day of appearance of } \\
\text { wound infection }\end{array}$ \\
\hline $\begin{array}{l}\text { Within 5 } \\
\text { days }\end{array}$ & $6-10$ days & $\begin{array}{l}\text { Beyond } \\
10 \text { days }\end{array}$ \\
\hline $22 \%$ & $52 \%$ & $25 \%$ \\
\hline
\end{tabular}

\section{Discussion:}

In the present study incidence of post operative wound infection was $7.47 \%$ among the patients who underwent major abdominal surgeries in Obstetrics and Gynaecology department (Unit-I) which is almost similar (6\%) to the finding of Riou J-PA (1992) in a study ${ }^{6}$. According to the 2002 survey report by the Nosocomial Infection National Surveillance Service
(NINSS) incidence of hospital acquired infection related to surgical wound is as high as $10 \%{ }^{7}$.

As the respondents were recruited from the department of Gynaecology and obstetrics, so all were female and the study could not show any relation of sex with wound infection. The current study found no definite relationship between age and socio-economic status with wound infection. This was because the operated cases were more in similar age group and regarding socioeconomic status, majority of the people were from a particular area. Aziz MD (1997) also showed similar result in his study at Dhaka ${ }^{8}$. Davidson et al (1971) and Cruse and Foord (1973) found in their series that increasing age influence directly wound infection ${ }^{9,10}$.

In our study wound infection was more frequently in caesarean section than gynaecological surgeries (fig 1) and it was statistically significant $(\mathrm{P}$ value $=0.025)$. The incidence of prolonged rupture of membrane, prolonged labour, repeated internal examination in labour, trial of labour at home invites bacterial invasion and increases the chance of wound infection. Another author mentioned similar picture ${ }^{11}$.

Our study also found increase incidence of wound infection among the population under went emergency caesarean section than elective ones. The above mentioned conditions in labour are the factors lie behind this.

This study also found, the occurrence of post-operative wound infection was more $(60 \%)$ in multiparous women than in primaeparous and possibly malnutrition and anaemia due to repeated childbirth acted as the predisposing factors.

The study showed the appearance of infection between 6 and 10 post-operative day in more than half of the population (Table II). Similar result ( $8 \pm 2$ day post operatively) was found in a study by Matin ASMR $(1981)^{12}$. Haddad V and Macon WLN (1980) showed in their studies that the occurrence of wound infection was on an average of 6.8 post-operative days which was also similar to that of ours ${ }^{13}$. The time of appearance of wound infection in majority of the cases (6 to10 days) indicates that the source of infection was not from the operation theatre, rather from patients' surroundings like, patients' ward, attendance etc.

This study shows $70 \%$ of the populations were anaemic (Fig 4), though severe and moderate anaemia was found in a negligible number of the patients. There was a strong relationship between anaemia and wound infection $(\mathrm{P}=0.04)$ in our study as was found by Zaman F (2011) in her study. ${ }^{14}$

Among the wound infection of this series $50 \%$ was presented with serosanguinous discharge (Fig 3). Almost 
J. Dhaka National Med. Coll. Hos. 2011; 18 (01): 39-42 similar finding was noticed in a study by Zaman $\mathrm{F}$ at ICMH , Dhaka ${ }^{14}$.

Figure 5 shows diabetes in $27.5 \%$ patients of postoperative wound infection which was also statistically significant $(\mathrm{P}=0.003)$. Hansis $\mathrm{M}$ (1996) also found diabetes as an important factor of post-operative wound infection ${ }^{1}$.

In the bacteriological study of the wound discharge we found the growth of organism in $65 \%$ cases. Of them growth of Staphylococcus aureas was noticed in majority of the cases (Fig 2). Several studies found that staphylococcus has a greater propensity to cause infection ${ }^{3,4}$.We also found no growth in $35 \%$ population which was possibly due to the use of antibiotic.

\section{Conclusion and recommendation:}

The study highlights on the possible etiology of wound infection. It is evident that wound infection has a close relationship between anaemia, raised blood sugar, emergency operations specially caesarean section and multiparity. Staphylococcus aureus was found the most common microorganism causing wound infection.

Though surgical care is very important to prevent wound infection, but some pre and post operative steps can reduce post operative wound infections also. If we can eradicate anaemia in pregnancy, control diabetes, avoid prolonged labour, use potent antibiotics in cases of rupture of membrane, do timely intervention, provide well equipped obstetrics ward with clean environment, then incidence of wound infection can be lowered.

As the size of the population in the current study was small and it was limited to one hospital, so it could not represent the picture of wound infection of whole population of Bangladesh. Therefore large scale studies of longer duration are necessary.

\section{References:}

1. Hansis M. Pathophysiology of infection.Injury,1996;27 suppl 3:sc5-8

2. Hedig Pelle MD, Ole B Japsen, Severin O Larsen, Jens Bo, Fleming Christensen, Anne Dreisler et al. Wound inection after caesarean section. Infection Control. Vol 7, No (Sep, 1986), pp, 456-461

3.Emmerson M. A microbiologist's view of factors contributing to infection, New Horiz. 1998 May,6(2 suppl):S3-10..)

4.deSa LA, Sathe MJ, Bapat RD. Factors influencing wound infection (a prospective study of 280 cases). J Postgrad Med [serial online] 1984 [cited 2012 Jan 26 ];30:232-6

5. Pollock AV, Greenal MG, Evans M. Single layer mass closure of major laparotomies by continuous suturing: JR Soc Med. 1979; 72: 889-93

6. Riou J-PA, Cohen JR, Johnson H Jr, Factors influencing wound dehiscence: Am J Surg. 1992; 163: 324-30).

7. NINSS. Surveillance of the Surgical Site Infection in English Hospitals: a national surveillance and quality improvement programme. Public Health Laboratory Service, 2002.

8.Aziz MD. Study of aetiopathology of abdominal wound dehiscence ( Dissertation). Dhaka: BCPS, 1997.

9. Davidson, A. I. G., Clark, G. and Smith, G.: Post-operative wound infection - A computer analysis. Brit. J. Surg., 58: 333337, $1971 b$.

10. Cruse, P. J. E. and Foord. R.: A 5-year prospective study of 23,649 surgical wounds. Arch. Surg., 107: 206-210, 1973.

11. Decherney A.H, Nathan L.MD, post partum hemorrhage and the abnormal puerperium: Current Obstetric and Gynaecologic Diagnosis and Treatment, $9^{\text {th }}$ edition.McGraw Hill, USA. 2004.

12. Matin ASMR. Wound Infection in Planned Abdominal Surgery. (Dissertation), Bangladesh College of Physicians and Surgeons, 1981.

13. Haddad V, Macon WLN. Abdominal Wound Dehiscence and Evisceration: Contributing factors and improved mortality, Br J Surg. 1980;16:508-13

14. Zaman F. Profile of wound infection following caesarean section delivery at Institute of Child \& Mother health, Matuail, Dhaka.(Dissertation), Bangladesh College of Physicians and Surgeons, 2011. 